\title{
Negative Pressure Wound Therapy (NPWT) in Breast Surgery
}

\author{
Abdalla Saad Abdalla Al-Zawi, Vanessa Salih, Amira Asaad, Rebecca Harsten, Momen Abdou Alkhir, Hamad \\ BenRafe, Tomasz Banasiewicz
}

\section{REVIEW}

\begin{abstract}
Background: The use of Negative Pressure Wound Dressing has been found to promote the wound healing process, therefore, reducing the risk of surgical site complications. The use of this technique amongst breast cancer patients, who have often encountered a distressing journey, may prove beneficial in making the post-operative process less eventful. Many of these patients have a limited time window to start adjuvant treatment. The use of a negative pressure device is recommended in both prophylactic and therapeutic scenarios. NPWT may also be used in patients who have undergone cosmetic breast surgery. We have evaluated the use of NPWT in breast surgery with an updated and systematic review of the available literature.

Methods: The authors systematically searched the PubMed, Science Direct, and Wiley Online databases using the phrases "Negative Pressure Wound Therapy in Breast surgery" and "Vacuum-Assisted Closure in Breast Wound" and all publications, including relevant data were considered eligible for inclusion in the review.

Results: We have found reports of 7 studies, 3 retrospective, 2 prospective, one randomized trial, and one case series. The complication rate in the NPWT group versus conventional dressing group has been reported in 5 papers. A statistically significant effect in favor of NPWT was documented in three trials.

Conclusion: The current evidence supports the notion that NPWT systems are beneficial in enhancing the healing of complicated breast wounds. However, larger studies exploring the effectiveness of this technique would be of interest to breast surgeons.
\end{abstract}

Keywords-Negative Pressure Wound Therapy, vacuumassisted closure, Breast cancer, Breast reconstruction

\section{INTRODUCTION}

T HE scope of breast surgery includes the management of benign and malignant breast disease either by mastectomy with or without reconstruction (autologous tissue as well as implant-based) or breast conservative surgery.

Manuscript received 03.08.2019; revised 17.12.2019. This work did not receive any financial support.

Author affiliations: Department of Surgery, Basildon \& Thurrock University Hospital, Essex, United Kingdom, (ASAA, AA)

Department of Surgery, Kings College Hospital, London, United Kingdom, (VS) ; Lewisham and Greenwich NHS Trust, London- United Kingdom, (RH) ; Morzoque Faculty of Medical Technology, Sebha University - Libya, (MAA) ; Faculty of Medicine, Omar Al-Mukhtar University, Al-Baida-Libya, (HB) ; Department of General, Endocrine Surgery and Gastrointestinal Oncology, Poznań University of Medical Sciences, Poznań, Poland, (TB)

*Correspondence to: Abdalla Saad Abdalla Al-Zawi: abdalasaad@gmail.com
Furthermore, it also encompasses aesthetic surgery such as breast augmentation or reduction. Complications associated with the post-operative wound-healing process remain one of the most common challenges and are potentially associated with delaying adjuvant therapy and diminishing the aesthetic result.

The benefits of using the Negative Pressure Wound Dressing in Breast surgery have been well documented.

Breast cancer is considered the most frequently detected female malignancy worldwide and the dominant cause of cancer-related mortality amongst women. 1 Although breast surgery is typically associated with a low risk of surgical site infection (SSI), the use of the Negative Pressure Wound Dressing further results in a favorable outcome.

We have studied available data that discuss the effectiveness of negative pressure wound therapy (NPWT) systems in the management of post-surgical wounds involving the breast.

\section{Methods}

The PRISMA principles have been followed during this review preparation. The PubMed, Science Direct, Wiley Online databases, and Scopus databases have been searched systematically. All the papers that revealed relevant data were considered eligible for inclusion in the review.

\section{INCLUSION CRITERIA}

We have looked at studies involving patients that underwent surgical breast procedures. The intervention under exploration was the use of NPWT in postoperative wounds. The comparator treatment was conventional dressings including dry wound dressing, alginate dressings or salinesoaked gauze dressings. Original papers such as randomized controlled trials (RCTs), retrospective studies, prospective studies, and case series have been included and the full text of the paper was explored. Papers that do not refer to the use of NPWT in breast surgery were excluded. The primary outcome was complete wound closure. No minimum patient sample size per trial was required and no restriction was placed for study dates or periods. After selection, seven original research papers met the inclusion criteria and were finally included in this review,(one randomized trial, three cohort retrospective studies, two prospective studies, and one 


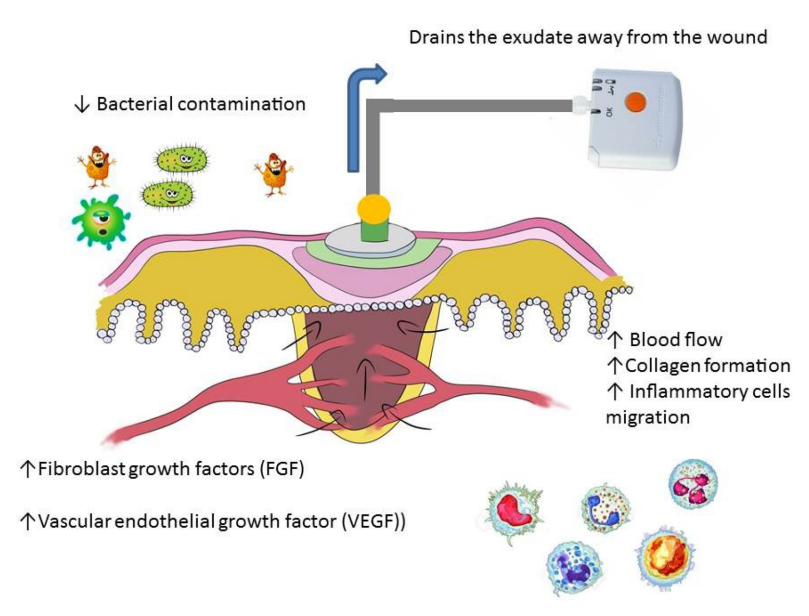

Figure 1. Mechanism of action in negative pressure wound therapy. Modified from Bruke et al. 2014

case series). The studies involved 492 female patients treated with NPWT versus 584 patients treated with conventional dressing methods.

\section{Results}

\section{A. Mechanism of action}

The use of Negative Pressure Wound Dressing promotes wound healing by triggering several healing pathways i.e. angiogenesis which improves tissue oxygenation and aids migrating the inflammatory cells to the healing site. It also aids the diversion of the wound exudate away from the wound and promotes patient independence and improves quality of life. $2 \sqrt{4}$

\section{B. Device types and indications}

The current devices that provide NPWT are vacuumassisted closure (VAC) system and $\mathrm{PICO}^{\mathrm{TM}}$ dressing. The $\mathrm{PICO}^{\mathrm{TM}}$ dressing is a canister free; single-use topical NPWT system that maintains $-80 \mathrm{mmHg}$ pressure (Fig. 2). The NPWT systems are used to manage complex wounds such as those which are infected, diabetic foot ulcers, post-traumatic wounds, burns, and necrotizing fasciitis. $[5$

NPWT concept is continually evolving. In addition to the use of conventional NPWT it may also be used to manage post-surgical wound complications or as a prophylactic measure to reduce the infection risk ${ }^{6}$ Negative Pressure Wound Therapy with the installation system (NPWTi) has also been developed. It incorporates the traditional NPWT and a local irrigation system within the wound cavity. NPWTi significantly reduces the growth of biofilm that colonize the wound cavity. Such formation of biofilm is considered to be one of the main factors impairing the wound healing process. ${ }^{7}$

Stoeckel et al. retrospectively analyzed the data of 18 patients who had post-operative breast wound complications treated with NPWT. 15 of the patients underwent surgery for breast cancer, two had reduction mammoplasty, and one

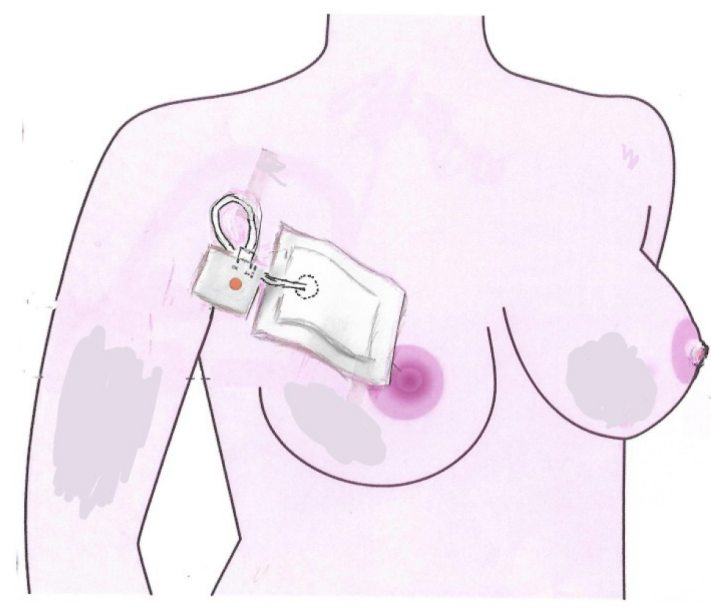

Figure 2. $\mathrm{PICO}^{\mathrm{TM}}$ dressing in breast surgery

was treated for a recurrent primary breast abscess. 12 of the 15 cancer patients underwent mastectomy had subsequent breast reconstruction procedures. Seven wounds were related to implant or tissue expander placement. Four patients had complicated transverse rectus abdominus myocutaneous (TRAM) flap wounds, and one had a latissimus dorsi flap wound. 15 of 18 patients were treated effectively using NPWT. Two patients required muscle flap coverage. The hospital stay ranged from 3 to 54 days with a mean of 12.1 days. NPWT dressing has been used to promote wound healing after skin grafting, or as a mean to prepare the wound for surgical closure. Seven of the wounds healed by secondary intention, six were successfully treated with subsequent skin grafting, and two were treated with delayed primary closure. Two wounds were both complicated by tissue ischemia and infection requiring operative debridement (Tab. I). The authors concluded that vacuum-assisted closure therapy promotes faster healing and stimulates the formation of healthy granulation tissue $\frac{8}{8}$

\section{NPWT in oncoplastic breast surgery boosts incision clo- sure}

Holt and Murphy from South Manchester University Hospital conducted a study to assess if the application of negative pressure wound therapy dressings $\left(\mathrm{PICO}^{\mathrm{TM}}\right)$ on closed incisions in patients undergoing therapeutic resection promotes superior wound healing. 24 consecutive patients (over 20 months) were included in the study. They either underwent a therapeutic mammoplasty or skin-sparing mastectomy and immediate reconstruction with inferior dermal flap and implant placement. All patients had a simultaneous symmetric breast reduction at the same sitting. The therapeutic procedure side was supplied with $\mathrm{PICO}^{\mathrm{TM}}$ dressings while the opposite breast reduction was dressed with conventional dressings. The overall rate of wound dehiscence was $4.2 \%$ $(\mathrm{n}=1)$ on the therapeutic procedure side compared with $16.7 \%(n=4)$ on the contralateral breast reduction side. The mean time to complete healing was 10.7 days in the therapeutic side treated with $\mathrm{PICO}^{\mathrm{TM}}$ compared with 16.1 
days on the contralateral side. One mastectomy patient had delayed wound healing at the T-junction on both sides (Tab. I). The authors concluded that this evidence further supports the use of NPWT in oncoplastic breast procedures, as it reduces the rates of wound dehiscence, boosts healing, and allows commencement of adjuvant therapy. ${ }^{9}$

Ferrando et al. conducted a prospective study that included 37 cases. ciNPT was used in 17 cases $(46 \%)$, whereas the remaining $20(54 \%)$ had conventional post-operative wound dressing. The difference in complication rate between the 2 groups was significant, the ciNPT sample showed complication rates of only $1 / 25(4 \%)$, as compared to $45 \%$ (10 out of 22 ) in the standard care group (Tab. I). The study outcome supports the use of ciNPT in oncological breast surgery. Furthermore, the dressing is well-tolerated, adaptable, and has shown to improve scar outcomes especially in patients presenting with high-risk factors $\frac{10}{10}$

Gabriel et al. investigated closed incision Negative Pressure Therapy (ciNPT) with a customizable dressing on 13 patients ( 25 breasts) who received immediate postmastectomy reconstruction as part of 2-stage expander/implant breast reconstruction. Nipple-sparing mastectomy was performed on 14 breasts, reduction-pattern mastectomy on 6 breasts, and skin-sparing mastectomy on 5 breasts. All post-mastectomy incisions were managed with ciNPT. The single-use therapy unit provided continuous negative pressure $(-125 \mathrm{mmHg})$ with a replaceable $45 \mathrm{ml}$ exudate canister. The wound dressing and ciNPT unit were designed for placement for up to 7 days. Surgical drains were routed under the skin beyond the ciNPT dressing and they functioned independently of ciNPT . The majority of patients $(56.0 \%)$ were treated with nipplesparing mastectomy. Overall mean ciNPT duration ranged from 3 to 5 days. The mean drain placement was 8.2 days. After three months follow-up, 96\% (24/25 breasts) achieved complete healing. Superficial dehiscence occurred in $12 \%$ (3/25 breasts), and flap necrosis occurred in 4\% (1/25 breasts) in the breast reduction-pattern group. One patient from the nipple-sparing mastectomy group developed a delayed hematoma postoperatively. No superficial wound dehiscence required surgical intervention. One obese, diabetic patient developed a flap necrosis which required surgical revision. All other breasts healed and remained closed at 3-month follow-up (Tab. I). The paper concluded that ciNPT could be a viable option for wounds after immediate post-mastectomy reconstruction. 11

In a cohort of 206 patients (228 breasts), Kim et al. examined the usefulness of the ciNPT to reduce mastectomy flap necrosis in immediate expander-based breast reconstruction. The incisional-NPWT group (45 breasts) had a lower overall complication rate in comparison with a conventional dressing group $(11.1 \%$ vs. $27.9 \%, \mathrm{p}=0.019)$. In detail, the overall mastectomy flap necrosis rate was $8.9 \%$ (versus $23.5 \%$; $\mathrm{p}=$ 0.030 ), and major mastectomy flap necrosis rate was $2.2 \%$ (versus $13.7 \% ; \mathrm{p}=0.031$ compared with the conventional dressing group, Tab. I). The paper concluded that the use of NPWT is an effective method in reducing mastectomy flap necrosis in expander-based breast reconstruction! 12

Gabriel et al. conducted a retrospective study comparing postoperative outcomes in patients who were treated with ciNPT versus standard of care (SOC) after breast reconstruction following mastectomy procedures. The authors investigated the medical records of 356 patients (ciNPT $=177$, SOC $=179)$ with 665 closed breast incisions $($ ciNPT $=331$, SOC $=334)$. Overall complication rate was $8.5 \%(28 / 331)$ in ciNPT group compared with $15.9 \%(53 / 334)$ in SOC group $(\mathrm{p}=0.0092)$. Compared with the SOC group, the ciNPT group had significantly lower infection rates $(7 / 331(2.1 \%)$ versus $15 / 334(4.5 \%)$, respectively; $\mathrm{p}=0.0225)$. Time to complete drain removal per breast for ciNPT versus SOC groups was 9.9 versus 13.1 days $(\mathrm{p}<0.0001)$, respectively. Patients who received ciNPT over closed incisions following mastectomy and breast reconstruction experienced a shorter time to surgical drain removal and significantly lower rates of infection, dehiscence, necrosis, and seromas, compared with the SOC group 13

\section{NPWT in breast surgery transplants}

Angspatt et al. in 2017 evaluated the efficacy of NPWT in preventing donor site seroma formation after the harvest of a latissimus dorsi muscle flap for breast reconstruction. It was a prospective matched-pair study, 40 patients were included. 20 patients had NPWT dressing at the donor site, and conventional wound dressing was used in the control group $(n=20)$. In the NPWT group, seroma incidence after the drain removal was significantly lower than in the control group (15\% vs. $70 \%$; odds ratio $=0.07$, relative risk, 0.24$)$. Both the mean percutaneous aspirated volume $(\mathrm{p}=0.004)$ and the frequency of percutaneous aspirations $(\mathrm{p}=0.001)$ were also significantly lower in the NPWT group (Tab. II). The paper concluded that the use of NPWT reduces the seroma incidence after drain removal from the latissimus dorsi flap harvesting site. 14

\section{E. ciNPT after reduction mammoplasty decreases wound dehiscence risk}

Galiano et al. presented a multinational, prospective, randomized, open trial to evaluate the efficacy of $\mathrm{PICO}^{\mathrm{TM}}$ (canister free; single-use NPWT system) on the prevention of post-surgical incision healing complications in 200 patients undergoing bilateral reduction mammoplasty (Tab. II). One patient arm was treated with $\mathrm{PICO}^{\mathrm{TM}}$ on one breast and Steristrips on the contralateral side. This group was assessed for local wound complications three weeks after the operation. Secondary objectives were to assess post-surgical complications (such as skin necrosis, hematoma, wound dehiscence and seromas), scar quality and the ease of application of $\mathrm{PICO}^{\mathrm{TM}}$ versus standard wound care. The outcome revealed a trend towards fewer complications and adverse events in the PICO $^{\mathrm{TM}}$ group compared to conventional wound care. Results also found a $38 \%$ decrease in wound dehiscence, which was statistically significant. 15

\section{F. Complex cases}

NPWT can also be used to manage complex postoperative complications relating to breast implant placement such as 
Table I

NPWT in Breast Oncoplastic Surgery

\begin{tabular}{|c|c|c|c|c|c|}
\hline Author & $\begin{array}{l}\text { Age } \\
\text { range }\end{array}$ & $\begin{array}{l}\text { Patient } \\
\text { number, } \\
\text { Breast } \\
\text { number }\end{array}$ & $\begin{array}{l}\text { Complications } \\
\text { rates in NPWT } \\
\text { vs. Conventional } \\
\text { methods }\end{array}$ & $\begin{array}{l}\text { Mean } \\
\text { NPWT } \\
\text { duration } \\
\text { (days) }\end{array}$ & Outcome \\
\hline $\begin{array}{l}\text { Stoeckel et al. } 2006 \\
\text { Retrospective study }\end{array}$ & Mean 52 & $\begin{array}{l}\mathrm{T}: 18,(18) \\
\mathrm{C}: 0,(0)\end{array}$ & no data & 15 & $\begin{array}{l}\text { Fifteen of the } 18 \text { patients were } \\
\text { definitively treated with the VAC }\end{array}$ \\
\hline $\begin{array}{l}\text { Holt et al. } 2015 \\
\text { case series }\end{array}$ & $42-70$ & $\begin{array}{l}\mathrm{T}: 24,(24) \\
\mathrm{C}: 24,(24)\end{array}$ & $\begin{array}{l}1 / 24(4.2 \%) \text { vs. } \\
4 / 24(16.7 \%)\end{array}$ & 6 & $\begin{array}{l}\text { The study further supports the use } \\
\text { of negative pressure wound therapy } \\
\text { on incised wounds }\end{array}$ \\
\hline $\begin{array}{l}\text { Gabriel et al. } 2016 \\
\text { retrospective cohort study }\end{array}$ & $27-62$ & $\begin{array}{l}\text { T: } 13,(26) \\
\text { C: } 0,(0)\end{array}$ & $\begin{array}{l}5 / 26(19 \%) \text { vs. } \\
\text { no data }\end{array}$ & 4.3 & $\begin{array}{l}\text { By 3-month follow-up } 24 \text { of } 25 \\
(96 \%) \text { breasts achieved healing. }\end{array}$ \\
\hline $\begin{array}{l}\text { Kim et al. } 2016 \\
\text { prospective cohort study }\end{array}$ & $34-49$ & $\begin{array}{l}\mathrm{T}: 44,(45) \\
\mathrm{C}: 162,(183)\end{array}$ & $\begin{array}{l}5 / 45(11.1 \%) \text { vs. } \\
51 / 183(27.9 \%)\end{array}$ & 3 & $\begin{array}{l}\text { The use of NPWT in patients } \\
\text { who underwent breast reconstruc- } \\
\text { tion significantly reduced the inci- } \\
\text { dence rates of overall wound re- } \\
\text { lated complications. }\end{array}$ \\
\hline $\begin{array}{l}\text { Galiano et al. } 2018 \\
\text { international, RCT }\end{array}$ & $18-65$ & $\begin{array}{l}\text { T: } 199,(199) \\
\text { C: } 199,(199)\end{array}$ & $\begin{array}{l}113(56.8 \%) \text { vs. } \\
123(61.8 \%)\end{array}$ & 14 & $\begin{array}{l}\text { NPWT group had fewer healing } \\
\text { complications than the conven- } \\
\text { tional dressing group }\end{array}$ \\
\hline $\begin{array}{l}\text { Gabriel et al. } 2018 \\
\text { retrospective cohort study }\end{array}$ & $40-64$ & $\begin{array}{l}\mathrm{T}: 177,(331) \\
\mathrm{C}: 179,(334)\end{array}$ & $\begin{array}{l}28(8.5 \%) \text { vs. } \\
53(15.9 \%)\end{array}$ & 9 & $\begin{array}{l}\text { Patients who received ciNPT over } \\
\text { closed incisions experienced sig- } \\
\text { nificantly lower rates of wound } \\
\text { complications, compared with the } \\
\text { SOC group }\end{array}$ \\
\hline $\begin{array}{l}\text { Ferrando et al. } 2018 \\
\text { prospective cohort study }\end{array}$ & no data & $\begin{array}{l}\mathrm{T}: 17,(25) \\
\mathrm{C}: 20,(22)\end{array}$ & $\begin{array}{l}1 / 25(4 \%) \text { vs. } \\
10 / 22(45 \%)\end{array}$ & 7 & $\begin{array}{l}\text { The results support the use of } \\
\text { ciNPT in oncological breast } \\
\text { surgery }\end{array}$ \\
\hline
\end{tabular}

* ciNPT; Closed Incision Negative Pressure Therapy, SOC: Standard Care of Therapy The complications included superficial dehiscence, skin flap necrosis infection, seroma, haematoma and exposed implant, T: Patients treated with NPWT methods, Breasts number, C: Patients treated with conventional methods, Breasts number, RCT - randomized control trial

implant exposure after Acellular Dermal Matrix (ADM) reconstruction or following Nipple Area Complex (NAC) sparing mastectomy. The NPWT allows for a rapid implant replacement after the implant pocket infection has been resolved 16 Risk factors promoting surgical site infections include high BMI, diabetes mellitus, hypoalbuminemia, smoking, status post-chemotherapy, COPD, anemia, and immunecompromised patients. NPWT provides a safe alternative in such populations.

\section{G. Surgical Site Infection and NPWT}

It has been reported that NPWT, when applied prophylactically to a closed surgical wound, results in a decrease in the incidence of wound complications such as infection or collection of fluid. ${ }^{15}$ Strugala et al., in 2017 , conducted a meta-analysis to determine the impact of prophylactic use of NPWT on SSI, wound dehiscence and length of hospital stay. The outcome revealed a significant reduction of SSI from $12.5 \%$ to $5.2 \%$ with NPWT use. Wound dehiscence rate was reduced from $17.4 \%$ to $12.8 \%$ with NPWT, and the mean reduction in hospital length of stay (in patients treated with NPWT) was also significant $(-0.47$ days $)$. Such observations also encourage the use of NPWT in a wide range of abdominal, orthopedic and colorectal procedures 18

Post-operative wound-related complications following breast surgery varies from 7 to $31 \%$ in the literature 19
Consequences include a prolonged hospital stay, delay in adjuvant treatment delivery, poor cosmesis, the need for further surgery and increased management costs. Furthermore, the use of negative pressure wound dressing and its associated benefits in reducing complications plays a part in easing a patient's psychological stress in the post-operative period.

\section{Conclusion}

One in eight women is affected by breast cancer during their lifetime and surgery is an essential element in the management pathway!21 As the majority of breast cancer patients will require adjuvant treatment after surgery, swift recovery is essential in preventing delays. Such delays ultimately affect outcome and survival. Furthermore, NPWT may play a role in improving the cosmetic outcome by reducing the tension in the surgical wound, obliteration of the dead space and minimizing tissue injury by protecting the wound from contamination and infection. ${ }^{22}$ Randomized controlled clinical trials that are currently under progress will show if the NPWT is able to provide women underging immediate breast reconstruction, better outcomes due to a faster healing process and superior aesthetic results when compared to the conventional post-operative wound dressings. $\stackrel{23}{ }$

The current evidence supports the notion that NPWT systems are beneficial in enhancing the healing of complicated breast wounds. However, larger studies exploring the effectiveness of this technique are required. 


\section{ACKNOWLEDGMENT}

We would like to thank Rihana Saad Abdalla from the BMAT STEM Academy School, in Harlow-England and Jakub Saad Abdalla from the Pemberley Academy Primary School in Harlow-England for their extra-ordinary work to prepare some of the included figures.

\section{REFERENCES}

[1] A. S. A. Al-Zawi, A. Lazarevska, M. M. Omer, E. Tan, A. Asaad, and S. Sathananthan, "Metastatic breast cancer to the cervix presenting with abnormal vaginal bleeding during chemotherapy: A case report and literature review," Chirurgia, vol. 113, pp. 564-570, 2018.

[2] T. Banasiewicz, "Npwt sentenced to success," Negative Pressure Wound Therapy, vol. 1, pp. 1-4, 2014.

[3] T. Awad and M. Butcher, "Handling the sequelae of breast cancer treatment: use of npwt to enhance patient independence," journal of wound care, vol. 22, no. 3, pp. 162-166, 2013.

[4] J. R. Burke, R. Morley, and M. Khanbhai, "Using portable negative pressure wound therapy devices in the home care setting," Smart Homecare Technology and TeleHealth, vol. 2, p. 129, 2014.

[5] R. Vidya, "Negative pressure dressing audit. royal wolverhampton nhs trust." [Online]. Available: http://picotrial.co.uk.

[6] T. Banasiewicz, A. Bobkiewicz, and M. Borejsza-Wysocki, "Portable vac therapy improve the results of the treatment of the pilonidal sinusrandomized prospective study," Polish Journal of Surgery, vol. 85, no. 7, pp. 371-376, 2013.

[7] A. Bobkiewicz, A. Studniarek, M. Drews, and T. Banasiewicz, "Negative pressure wound therapy with instillation (npwti): Current status, recommendations and perspectives in the context of modern wound therapy." Negative Pressure Wound Therapy Journal, vol. 3, no. 1, 2016.

[8] W. T. Stoeckel, L. David, E. A. Levine, A. E. Argenta, and N. D. Perrier, "Vacuum-assisted closure for the treatment of complex breast wounds," The Breast, vol. 15, no. 5, pp. 610-613, 2006.

[9] R. Holt and J. Murphy, "Pico ${ }^{\mathrm{TM}}$ incision closure in oncoplastic breast surgery: a case series," British Journal of Hospital Medicine, vol. 76, no. 4, pp. 217-223, 2015.

[10] P. M. Ferrando, A. Ala, R. Bussone, L. Bergamasco, F. A. Perinetti, and F. Malan, "Closed incision negative pressure therapy in oncological breast surgery: comparison with standard care dressings," Plastic and Reconstructive Surgery Global Open, vol. 6, no. 6, 2018.

[11] A. Gabriel, S. R. Sigalove, and G. P. Maxwell, "Initial experience using closed incision negative pressure therapy after immediate postmastectomy breast reconstruction," Plastic and Reconstructive Surgery Global Open, vol. 4, no. 7, 2016.
[12] D. Y. Kim, S.-J. Park, S.-I. Bang, G.-H. Mun, and J.-K. Pyon, "Does the use of incisional negative-pressure wound therapy prevent mastectomy flap necrosis in immediate expander-based breast reconstruction?" Plastic and reconstructive surgery, vol. 138, no. 3, pp. 558-566, 2016.

[13] A. Gabriel, S. Sigalove, N. Sigalove, T. Storm-Dickerson, J. Rice, P. Maxwell, and L. Griffin, "The impact of closed incision negative pressure therapy on postoperative breast reconstruction outcomes," Plastic and Reconstructive Surgery Global Open, vol. 6, no. 8, 2018.

[14] A. Angspatt, T. Laopiyasakul, P. Pungrasmi, and P. Suwajo, "The role of negative-pressure wound therapy in latissimus dorsi flap donor site seroma prevention: a cohort study," Archives of plastic surgery, vol. 44, no. 4, p. 308, 2017.

[15] R. D. Galiano, D. Hudson, J. Shin, R. Van Der Hulst, V. Tanaydin, R. Djohan, F. Duteille, J. Cockwill, S. Megginson, and E. Huddleston, "Incisional negative pressure wound therapy for prevention of wound healing complications following reduction mammaplasty," Plastic and Reconstructive Surgery Global Open, vol. 6, no. 1, 2018.

[16] A. Accurso, N. Rocco, G. Accardo, P. Reale, C. Salerno, E. Mattera, and F. D'Andrea, "Innovative management of implant exposure in adm/implant-based breast reconstruction with negative pressure wound therapy," Aesthetic plastic surgery, vol. 41, no. 1, pp. 36-39, 2017.

[17] E. K. Kostaras, G. S. Tansarli, and M. E. Falagas, "Use of negativepressure wound therapy in breast tissues: evaluation of the literature," Surgical infections, vol. 15, no. 6, pp. 679-685, 2014.

[18] V. Strugala and R. Martin, "Meta-analysis of comparative trials evaluating a prophylactic single-use negative pressure wound therapy system for the prevention of surgical site complications," Surgical infections, vol. 18, no. 7, pp. 810-819, 2017.

[19] P. Vikatmaa, V. Juutilainen, P. Kuukasjärvi, and A. Malmivaara, "Negative pressure wound therapy: a systematic review on effectiveness and safety," European Journal of Vascular and Endovascular Surgery, vol. 36, no. 4, pp. 438-448, 2008.

[20] M. S. Timmers, S. Le Cessie, P. Banwell, and G. N. Jukema, "The effects of varying degrees of pressure delivered by negative-pressure wound therapy on skin perfusion," Annals of plastic surgery, vol. 55, no. 6, pp. 665-671, 2005.

[21] A. S. A. Al-Zawi, M. Lange-Ratajczak, W. Chicken, S. Karamanakos, P. Idaewor, M. Elamass, E. Tan, and A. Asaad, "Pyloric metastases from primary breast cancer - a case report and literature review," JMSCR, vol. 5, no. 11, pp. 30098-30105, 2017.

[22] J. Ogden, "Improving outcome in complex patients - breast surgery.” [Online]. Available: https://improving-outcomes-online.com/ kom/breast-surgery

[23] T. Damsgaard, "Incisional negative pressure wound therapy (inpwt) in immediate breast reconstruction." [Online]. Available: https: //clinicaltrials.gov/ct2/show/NCT03069885 